\title{
Evaluation of Asphaltene Deposition - A Systematic Study and Validation of Online Focused Beam Reflectance Measurement FBRM ${ }^{\circledR}$ at Reservoir Conditions
}

Ruidiaz EM ${ }^{1 *}$, Koroishi ET ${ }^{1}, K_{\text {Kim NR}}^{1}$, Trevisan OV ${ }^{1}$, Soares-Bassani $\mathbf{G}^{2}$ and Merino-Garcia $\mathrm{D}^{3}$

${ }^{1}$ Center for Petroleum Studies, CEPETRO/UNICAMP, Campinas, São Paulo, Brazil

${ }^{2}$ Repsol Sinopec Brazil, Rio de Janeiro, Brazil

${ }^{3}$ Repsol, Madrid, Spain

\begin{abstract}
The production of crude oil from a reservoir is a challenging task. The handling of solids is one of the foremost assignments that operators may face during the life of a field. These solids may have the characteristics of both forms: inorganic material and organic material. The first one can be classified as salts and sand and the second comes from the crude oil that includes: waxes, asphaltenes, hydrates, and naphtenates. Apart from sand, the rest of the solids usually precipitate due to changes in composition (Commingling of fluids), temperature, or pressure. Asphaltenes precipitation is regarded to main issues referred to narrower mitigation strategy. Precipitate solid can produce reservoir blockage and in situ wettability change, decreasing well productivity widely. Know the operational conditions (PTx) under which the precipitation phenomena has been occurred is decisive, mainly the precipitation initial pressure (onset) and its velocity of formation. The purpose of this work consists in the experimental study of the asphaltenes precipitation from a crude oil sample under specific pressure and temperature representative of Brazilian pre salt reservoirs. In order to evaluate the impact of the operational conditions on solids formation and their relevant consequence to be used for petroleum exploration methods. The evaluation of solid formation was performed with Focused Beam Reflectance Measurement $\left(\mathrm{FBRM}^{\circledR}\right)$ at high pressure conditions, working with crude oil and live oil. The first stage involved the validation of asphaltenes precipitation for a batch system using crude oil and heptane at room conditions. The second one consisted in dynamic test carried out in a loop able to support pressures nearing 300 bars and temperatures up to $70^{\circ} \mathrm{C}$. Furthermore, an experimental methodology was developed in order to charge live oil into loop system. The measurements were monitored by online Focused Beam Reflectance Measurement FBRM ${ }^{\circledR}$. It was verified a greater count of asphaltene particles for range of 100-75 bars. There was more evidence in the asphaltenes precipitation in this period. It was possible to identify a pressure range combined to asphaltenes precipitation of target oil during depressurized system performed in successive stages. The pressure range combined with asphaltenes precipitation was revealed during the depressurization process that occurred in successive stages. Furthermore, the asphaltenes appearance was corroborated in the period of decrease from 100 to 75 bars. FBRM measurements allowed the asphaltenes appearance and growth for each stage of depressurization.
\end{abstract}

Keywords: Asphaltenes; Precipitation; Live oil; Focused Beam Reflectance Measurement (FBRM)

\section{Introduction}

As the reservoir pressure decreases, asphaltenes precipitation may occur, which are separated from the oil phase. Other causes that may lead to this phenomenon would be the change in temperature or composition. In maritime fields, the cost to remedy situations of asphaltenes can become invaluable, so the characteristics of these compounds need to be understood in the early stages of the field exploitation planning. The asphaltenes precipitation is one of the major technical problems with a more limited mitigation strategy; the squeeze, common treatment for other solids such as inorganic fouling, does not have a general applicability to the asphaltenes, and also require higher concentrations of inhibitor, creating a much larger impact on the economics of projects. The solid precipitate can cause blocking and modification of reservoir wettability, reducing well productivity.

Thus, it is of fundamental importance to know the PTx (pressure, temperature, composition) conditions under which the phenomenon happens, especially the initial precipitation pressure (onset) and the speed of the formation of solids.

The present work deals with a development of an experimental method to study asphaltene onset in high pressure flow. The asphaltenes precipitation begins when the fluid undergoes a pressure drop, as noted by Calles et al. [1]. This transition can be observed using the appliance FBRM, Focused Beam Reflectance Measurement.

The study of asphaltene onset includes experiments performed in a batch system and in a high pressure resistant circuit built in stainless steel, with accessories featuring control of temperature and pressure. A detection cell with an adaptation to place the probe of FBRM was developed.

\section{Theory - Asphaltenes Precipitation}

Asphaltene contains large and highly concentrated molecules,

"Corresponding author: Ruidiaz EM, Center for Petroleum Studies, CEPETRO/UNICAMP, Campinas, São Paulo, Brazil, Tel: +551935211196; E-mail: eddy@cepetro.unicamp.br

Received March 28, 2018; Accepted May 15, 2018; Published May 31, 2018

Citation: Ruidiaz EM, Koroishi ET, Kim NR, Trevisan OV, Soares-Bassani G, et al (2018) Evaluation of Asphaltene Deposition - A Systematic Study and Validation of Online Focused Beam Reflectance Measurement FBRM ${ }^{\circledast}$ at Reservoir Conditions. J Pet Environ Biotechnol 9: 364. doi: 10.4172/2157-7463.1000364

Copyright: @ 2018 Ruidiaz EM, et al. This is an open-access article distributed under the terms of the Creative Commons Attribution License, which permits unrestricted use, distribution, and reproduction in any medium, provided the original author and source are credited. 
Citation: Ruidiaz EM, Koroishi ET, Kim NR, Trevisan OV, Soares-Bassani G, et al. (2018) Evaluation of Asphaltene Deposition - A Systematic Study and Validation of Online Focused Beam Reflectance Measurement FBRM ${ }^{\circledR}$ at Reservoir Conditions. J Pet Environ Biotechnol 9: 364. doi: $10.4172 / 2157-7463.1000364$

Page 2 of 8

primarily hydrogen and carbon with heteroatoms and metals. Asphaltene can precipitate from the oil during the production process triggered by alterations in pressure, temperature, and oil composition. The precipitated asphaltene can deposit along the reservoir and production system plugging pore throats, wellbore, flowlines, or surface facilities, promoting serious production impairment [2].

Several experimental and analytic approaches have been studied referred to asphaltene precipitation outcomes. Some thermodynamic properties, such as: pressure, temperature and the crude oil composition can influence on the asphaltene precipitation [3].

Many research works have focused on determining the onset point of asphaltene precipitation [4-6] and also, other investigations have been carried out in order to measure the amount of asphaltene precipitated [3]

As the asphaltenes are defined in terms of their insolubility, this definition provides a broad distribution of molecular structures of asphaltenes that are precipitated from different crude oil samples. For certain crude oil sample, the yield and properties of the precipitated asphaltenes strongly depend on the specific precipitation method and precipitant used. Many standard precipitation methods have been developed in laboratory to obtain accurate and consistent asphaltene content.

Usually, asphaltenes are stable in oil phase at reservoir condition and the changes on temperature, pressure and composition of oil can induce asphaltene instability. Asphaltene stability in crude oil has been subject of investigations over many years.

Precipitation is defined as solid phase formation from the bulk liquid phase, primarily as a function of thermodynamic variables (i.e., temperature, pressure, and composition).

The commercial techniques need a minimum particle size, generally from about 0.5 to $1 \mu \mathrm{m}$, for asphaltene onset to be detected. The direct methods such as near infrared light scattering or optical microscopy can provide an indication of the presence of particles. These techniques have been used in order to detect the asphaltene onset, although they can detected after precipitated asphaltenes aggregate which is exceed the detection limit.

Onset is the minimum amount of precipitant required to induce the precipitation of solids, supposed to be asphaltenes. It is essential to detect when the precipitation is initiated and the quantity of asphaltenes that can be deposited during oil production, transportation, or processing in order to control and provide solutions promoters to the precipitation. The determination of the onset of precipitation accurately is important. Methods as conductivity, refractive index, viscosity measurements and spectroscopy have been used to measure the onset of precipitation or flocculation of asphaltenes [7].

In order to provide solutions to the precipitation problem, it is essential to investigate the beginning of precipitation is initiated. Also, it is required to know the quantity of asphaltenes which can be deposited in numerous stages such as oil production, transportation, and processing and oil recovery. Accurate determination of the onset of precipitation is therefore important.

\section{Operational Conditions that Influence the Asphaltenes Precipitation}

\section{Focused Beam Reflectance Measurement (FBRM)}

The FBRM probe uses a highly focused laser beam rotating at a high rate of speed and scans particles crossing the measurement zone. The laser light is backscattered as the particles intersect the beam. The duration of the backscatter is referred to the particle size and is expressed by chord length and the chord length distribution data (CLD) are measured as raw data [8].

The measurement method presents many advantages as: dilution is not required in most cases, higher suspension concentrations (up to $20 \%$ ) can be evaluated and the aggregating suspensions can be monitored in situ (e.g. in a stirred vessel), among others [9]. FBRM is able monitoring in situ particle size and solid concentration. FBRM probe can be inserted on-line or into a reaction vessel instantly and the installing of the pre-dilution side-stream is not required [10].

FBRM is a measurement instrument able to provide the chord length distributions. The chord length is the distance for which the laser beam crosses a particle. The probe is inserted into solution and projects an amply focused laser beam through the sapphire window and as the particles goes on by the window surface, the laser intersects with the edge of a particle and the particle backscatter light and measures the distance in which the laser beam crosses a particle [11-13].

\section{Methodology}

\section{Crude oil}

A crude oil sample from a Brazilian Pre-salt reservoir was used in all step of this work. Once a representative amount was taken from stock tank, a physicochemical characterization was carried out in order to obtain the saturate, resins, asphaltenes and aromatics fraction of each ones using an ASTM D6560-12 and ASTM D2007-11. Table 1 shows the results from SARA analysis.

\section{Live oil}

Live oil was obtained from a proper mixture between crude oil and a gas sample. The gas composition was mainly methane. Both fluids were into a pressurized container separately. The amount of gas was previously calculated in a ratio which represent a reservoir condition and depletion scenario, then this gas was pumping through the crude oil container and heated until reservoir temperature targets. The mixture was homogenized by stirring mechanically to reach equilibrium. Finally, was measured the ratio gas/oil in order to be sure that live oil was achieved.

\section{Batch setup for asphaltene identification}

The growing of asphaltene was initially identified following a trial of measurements in a batch setup. The Figure 1 displays the system with all components; a stirring mechanism running at $400 \mathrm{rpm}$, the glass volume rounding $400 \mathrm{ml}$ and FBRM probe can measure the signal at room temperature and pressure, while experiments were carried out.

\section{Loop setup for dynamic experiments}

A second trial of validation was carried out under dynamic conditions, followed in a loop system. Figure 2 shows the apparatus and its components regarding the pressure and temperature control. A

\begin{tabular}{|c|c|}
\hline \multicolumn{2}{|c|}{ SARA analysis, $\%(\mathbf{m} / \mathbf{m})$} \\
\hline Asphaltenes & 2.77 \\
\hline Resins & 26.87 \\
\hline Aromatics & 2.56 \\
\hline Saturates & 67.80 \\
\hline
\end{tabular}

Table 1: Crude oil composition 
Citation: Ruidiaz EM, Koroishi ET, Kim NR, Trevisan OV, Soares-Bassani G, et al. (2018) Evaluation of Asphaltene Deposition - A Systematic Study and Validation of Online Focused Beam Reflectance Measurement FBRM ${ }^{\circledR}$ at Reservoir Conditions. J Pet Environ Biotechnol 9: 364. doi: $10.4172 / 2157-7463.1000364$

Page 3 of 8

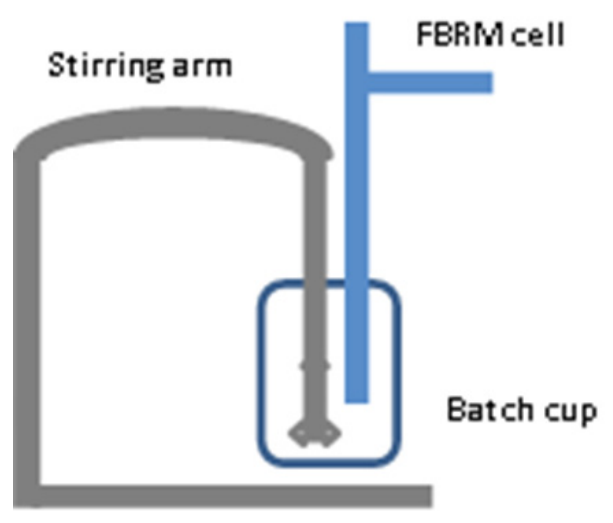

Figure 1: Batch setup.

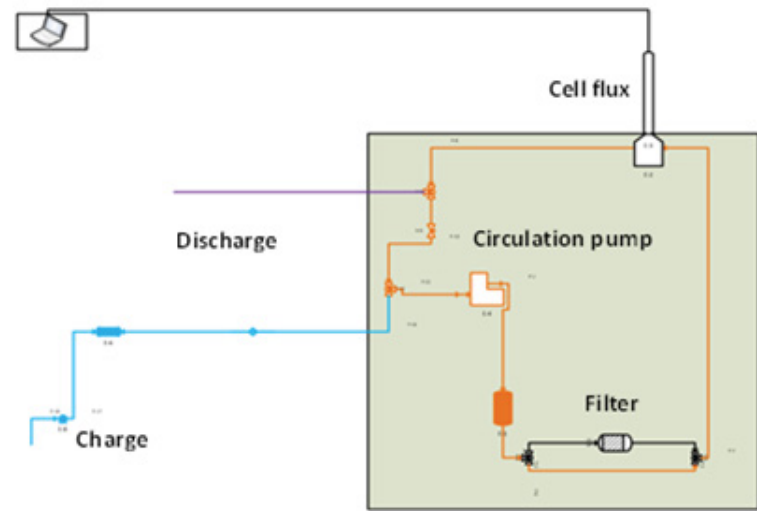

Figure 2: Loop system for high pressure running and study the asphaltene growing.

circulating pump (positive displacement pump QUIZIX) was used for mimic flood through the loop. A steel flux cell was designed for support high pressure and temperature conditions while the FBRM was kept online measuring the fluid. Also, a discharge line with backpressure device and a proper inlet with a check valve were added on the system in order to discharge the fluid. An additional circuit was composed by a high pressure filter for retention of asphaltenes molecules which being separately of crude oil due to decrease on pressure.

\section{Confirmation of asphaltenes growing in a batch condition}

The asphaltene precipitation was obtained putting a sample of crude oil in a batch system, stirring at $400 \mathrm{rpm}$ and added an adjusted ratio of heptane. A FBRM device was recording online the cord length while more heptane was added up to reach a final volumetric ratio. Two different ratios of crude oil and heptane were applied in order to obtain variation in a signal of FBRM showing the growing of asphaltenes.

\section{Validation of asphaltenes growing under dynamic conditions}

In the beginning, there was used the same procedure applied in batch system in order to obtain similar response in a dynamic loop. Therefore, the same crude oil and ratios of heptane were put on the loop. In this setup, crude oil was removed proportionally as heptane was introduced into the system. At the same time FBRM's was recording the values of chord length. The variation of signal was directly associated to asphaltene growing.

In a second stage of experiments, the live crude oil was introduced at 200 barss and $64^{\circ} \mathrm{C}$ in the same loop system. After reach a constant signal in the FBRM, it was followed a sequence of pressure decreasing; first, the pressure was decreased in steps of two hours by 50 bars until to reach the bubble point of crude oil. In this set of experiments, it was divided in two sections, one experiment was performed with live oil with a sample filtered and one experiment without crude oil filtrated. The second one was carried out only one step of pressure decreased. This allows measuring the capacity of growing of asphaltenes in the crude oil measured by FBRM.

\section{Results and Discussion}

\section{Initial asphaltene growing and FBRM measuring validation - Batch setup}

A systematic experiment was carried out in a batch setup in order to obtain representative values for asphaltenes precipitation with FBRM measures. Figure 3 displays the running for a sample of previous filtered crude oil which has starting at $400 \mathrm{rpm}$.

Then heptane was added in a ratio of 1:1 and 1:2 in volume and the system kept constant. As Figure 4 shown, the first blue line indicates the time of addition of heptane in a portion of 1:1. It can be seen that from

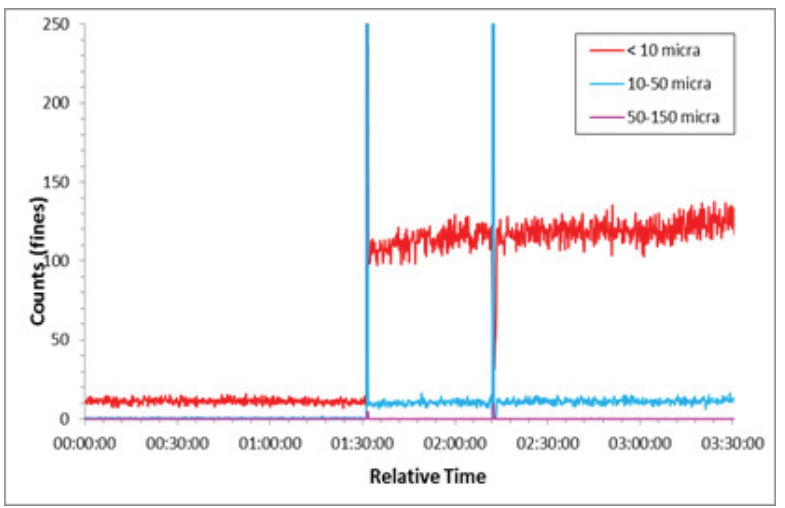

Figure 3: FBRM measure in a batch system containing crude/heptane - Ratio $1: 1$

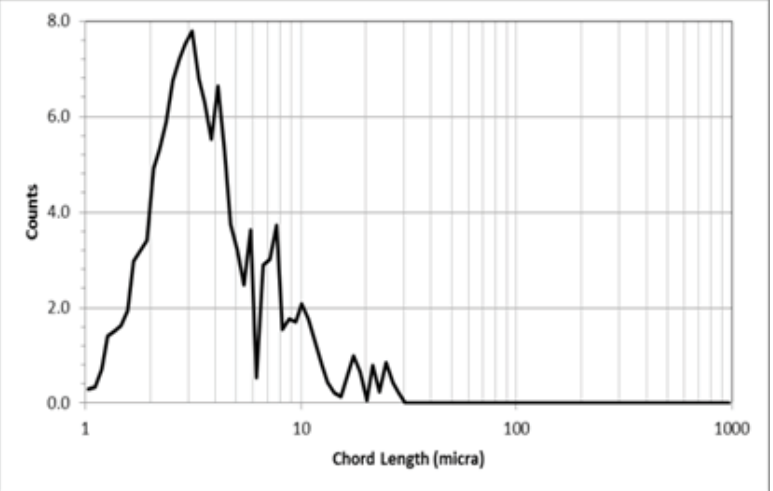

Figure 4: Distribution of chord length for the mixture crude/heptane. 
Citation: Ruidiaz EM, Koroishi ET, Kim NR, Trevisan OV, Soares-Bassani G, et al. (2018) Evaluation of Asphaltene Deposition - A Systematic Study and Validation of Online Focused Beam Reflectance Measurement FBRM ${ }^{\circledast}$ at Reservoir Conditions. J Pet Environ Biotechnol 9: 364. doi: $10.4172 / 2157-7463.1000364$

Page 4 of 8

this point two sizes of particles were obtaining, the particles count for the range of $<10$ micro increased approximately nine times. Therefore, this signal appears to be a separation of asphaltene from the oil phase. The second addition of heptane (second blue pick) exhibits the increase in both size particles keeping constant against time of running. With this initial batch, it was possible to obtain positive response of FBRM regarding the asphaltene separation from oil phase and successive growing.

A successive running was performed in the same setup. In this case, crude oil was added together with the crude oil sample as Figure 5 presents. The trend of growing can be identified for at least 12 hour of running giving values several times higher than crude oil reference to thank Lifu Zhou and Jiguang Tang support.

The evolution of asphaltene growing (Figure 5) between the crude oil signal and the mixture with heptane arise more straight due to the interaction of solvent which produce a separation from the oil phase allowing the sequential growing (Figure 6).

\section{Initial asphaltene growing and FBRM measuring validation - Loop system}

Figures 7 and 8 show the FBRM measure in a loop setup of the mixture of crude/heptane - Ratio 1:1 and the distribution of chord length for this system, respectively. For this experimental test, the mixture of crude/heptane - Ratio 1:1 was inserted in the loop and the behavior was monitored by FBRM measurements. There were two

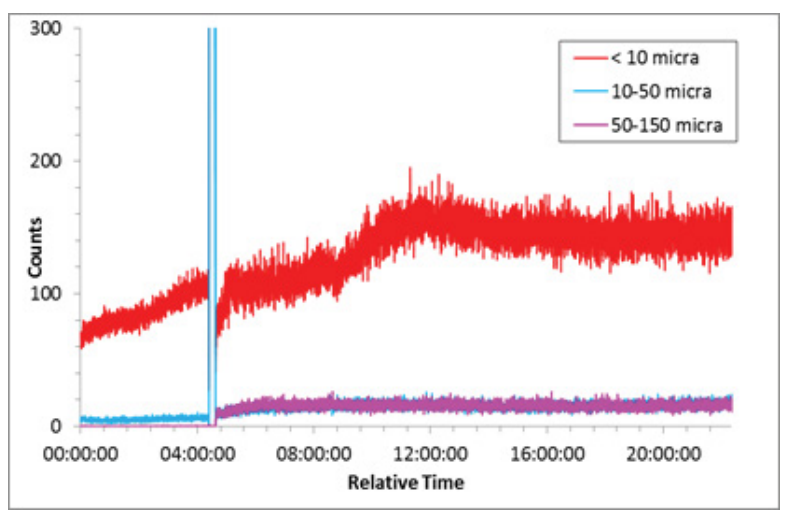

Figure 5: FBRM measure in a batch system containing crude/heptane Ratio $1: 2$

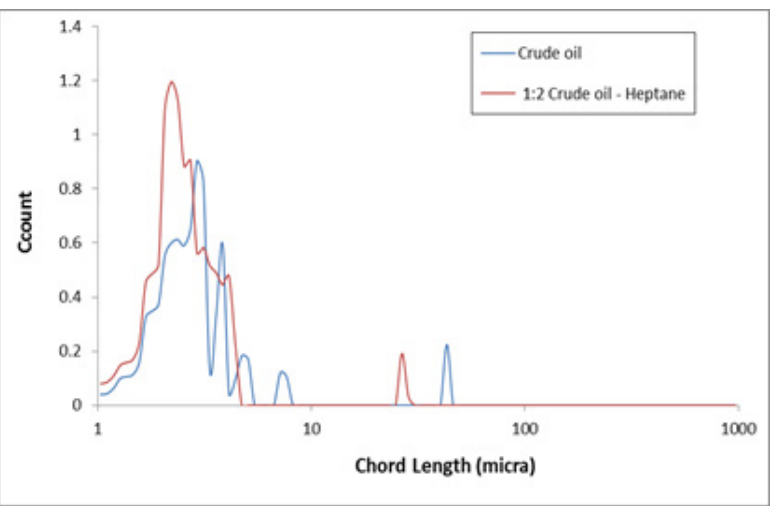

Figure 6: Distribution of chord length for the mixture crude/heptane - Ratio

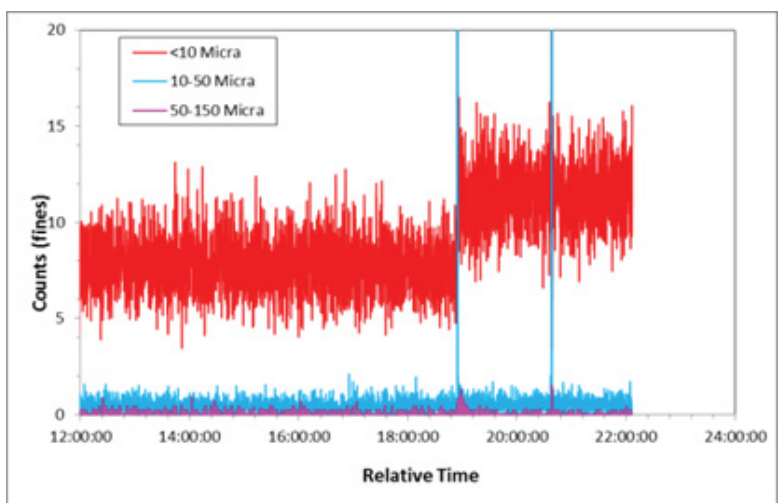

Figure 7: FBRM measure in a loop setup of the mixture of crude/heptane - Ratio 1:1.

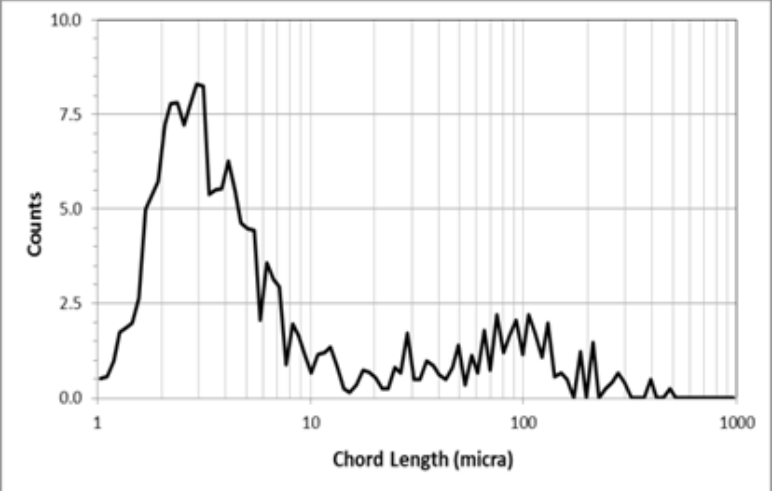

Figure 8: Distribution of chord length for loop system of the mixture crude/ heptane - Ratio $1: 1$

ranges for particles size. After 19 hours, it was observed that there was an increase of particles with range of $<10$ micro (Figure 7). Analyzing Figure 8, it can be verified two ranges of distribution of chord length; it is an indicative of separation from the oil phase and particles growing.

Figures 9 and 10 display the FBRM measure in a loop setup of the mixture of crude/heptane - Ratio 1:2 and the distribution of chord length, respectively. The same procedure was following as previous test, but using the mixture of crude/heptane - Ratio 1:2. The particles majority was located in the range of $<10$ micro as shown in Figure 9 and the statistical distribution was exhibited in Figure 10. It was noted that the great quantity of particles of the range of $<10$ micro had been integrated in this region.

\section{Asphaltene precipitation and growing under depletion scenario}

With the preparation stages completed, the circuit was properly charged with live oil at constant pressure, then the pressure was increased to 200 bars and the system monitored for 20 hours. In Figure 11 it can be seen that the count length distribution along the time evaluated the effect on decrease the pressure over the asphaltene growing and precipitation. After 12 hours passed, it appear to be more instability in the lecture of FBRM, which can be link to asphaltene growing while it flood through loop system.

After the system had been stabilized at 200 bars and $65^{\circ} \mathrm{C}$, it was 
Citation: Ruidiaz EM, Koroishi ET, Kim NR, Trevisan OV, Soares-Bassani G, et al. (2018) Evaluation of Asphaltene Deposition - A Systematic Study and Validation of Online Focused Beam Reflectance Measurement FBRM ${ }^{\circledR}$ at Reservoir Conditions. J Pet Environ Biotechnol 9: 364. doi: $10.4172 / 2157-7463.1000364$

Page 5 of 8

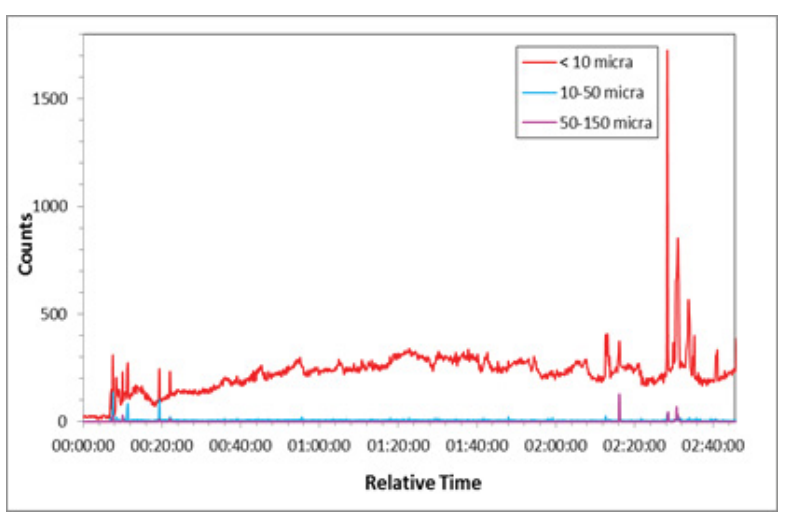

Figure 9: FBRM measure in a loop setup of the mixture of crude/heptane - Ratio 1:2.

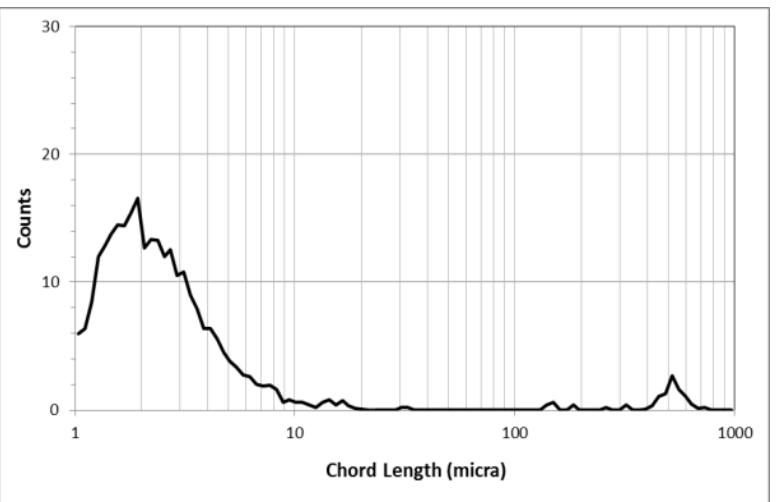

Figure 10: Distribution of chord length for loop system of the mixture crude/ heptane - Ratio 1:2.

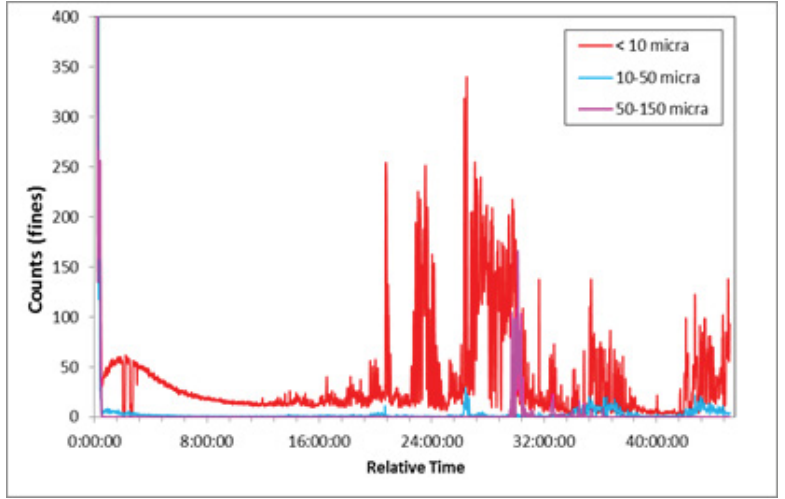

Figure 11: FBRM measure of live oil in a high pressure loop simulating a depletion scenario - pressure steps.

performed the depressurizing process in a single step, from 200 to 75 bars. Figure 12 displays the values of chord length and particle count during the first 30 minutes, collected at intervals approximately two hours, images were collected at 30 minute intervals for approximately nine hours of experiment. The experiment was concluded letting for another eight hours. During this experiment, the oil samples from filter installed at outlet system, the oil sample resulting of final test, the reference oil sample and the oil sample coming during cleaning were collected. Also, the solvent was sampled and the percentage of asphaltenes was determined using the ASTM standard. The result of these analyses presented in Table 2 shows the potential asphaltene growing and later the precipitation in the loop.

Figure 11 shows the behavior of the circuit at the time of live oil charged at a pressure of 200 bars and during the steps of depressurizing up to 50 bars. Figure 12 shows the comportment of the system for at least 19 hours exhibiting small variations in counting and a stable rope size distribution within the previously observed reference values (in a range of 1-10 microns). At the moment of the depressurizing, an increase in the count and the cut-off value of the order of 30 times in relation to the value reached during the stabilization were observed, as shown in Figures 11 and 12. After five minutes of the depressurizing, this value trended to decrease. During this time, it was possible to observe that the chord size distribution progressed to larger values, starting with a distribution close to 2 microns and moving up to 3-4 microns. This behavior was observed in the following 15 minutes observing that there are cycles of phase separation (crystallization of insoluble asphaltenes molecules) followed by agglomeration and coalescence due to laminar flow. The experiment was continued for nine hours where several images were collected and placed in a full picture with the appropriate sequence on the time scale.

At the end of the experiment, samples of the oil were collected and the asphaltenes content was presented (Table 1). As observed, the asphaltenes content in the circuit was significantly high, validating the coalescence theory of asphaltenes agglomerated and deposited in the flow line.

This experiment was carried out with a sample of non-filtered crude oil and methane properly prepared. After been stabilized was charged and stay running for 12 hours. The steps of decrease the pressure was follow as before. In each step the pump kept flood the live oil for two hour in order to obtain FBRM response linking the variation to asphaltene growing. When the loop reach 50 bars the circuit was

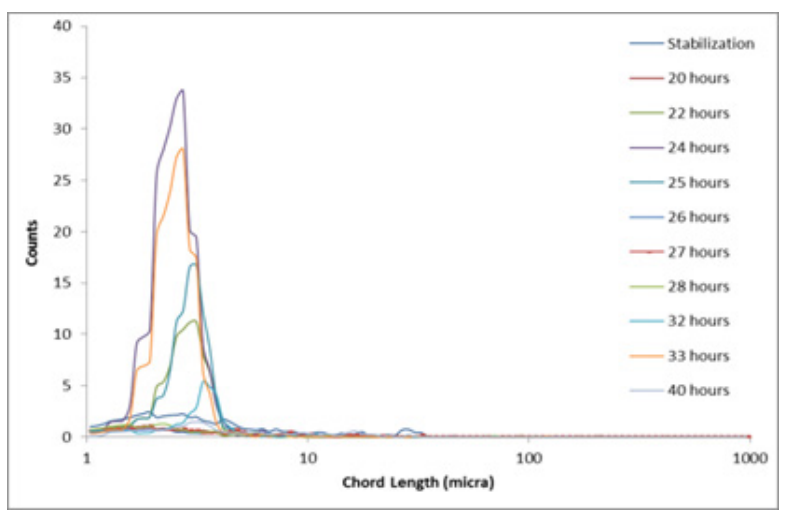

Figure 12: Distribution of chord length of the live oil decreasing steps.

\begin{tabular}{|c|c|}
\hline \multicolumn{2}{|c|}{ Asphaltenes analysis $\%(\mathbf{m} / \mathbf{m})$} \\
\hline Reference oil & 2.39 \\
\hline Asphaltene from cleaning loop & 0.89 \\
\hline Asphaltene filtered & 0.37 \\
\hline Asphaltene in oil after running & 1.13 \\
\hline
\end{tabular}

Table 2: Asphaltenes composition after running experiments in a loop setup. 
Citation: Ruidiaz EM, Koroishi ET, Kim NR, Trevisan OV, Soares-Bassani G, et al. (2018) Evaluation of Asphaltene Deposition - A Systematic Study and Validation of Online Focused Beam Reflectance Measurement FBRM ${ }^{\circledR}$ at Reservoir Conditions. J Pet Environ Biotechnol 9: 364. doi: $10.4172 / 2157-7463.1000364$

Page 6 of 8

turned through the by-pass which contained the high-pressure filter for a period of about 30 minutes (the approximate time all the fluid flows through the circuit). Then the by-pass is locked and simultaneously and the live oil continues flooding through the loop. Figure 13 shows the FBRM response during the live oil injection process at 200 bars and stabilization for two hours, the count at this stage was approximately 86. After stabilization, the trend observed in this step was the decrease in counting reaching values of 21 counts for particles $<10$ microns and below 1 for particles between 10-50 microns.

During the process of depressurizing the circuit unexpected depressurization occurred during stabilization and therefore it was not possible to decrease the pressure in the 200-150 bars step. As a result of this, an increase in the counting of $28 \%$ ( 6 counts) was observed for this stage. After reaching 125 bars pressure, an increase of approximately $52 \%$ was detected in relation to the reference of 21 counts (Figure 13). A similar increase was observed in the range of 10-50 microns particles.

At 100 bars of pressure, an increase in count was significant as $66 \%$ increase (relative to the test reference) for particles $<10$ microns, these results validate the hypothesis of the presence of asphaltenes in live oil, growing during depressurizing and FBRM can detects it. When the system was depressurized at 75 bars the counting increased to approximately double the observed count at the end of stabilization of the system at 200 bars. This confirms that the pressure range of 100-75 bars is critical in the crystallization of asphaltenes dissolved in the oil.

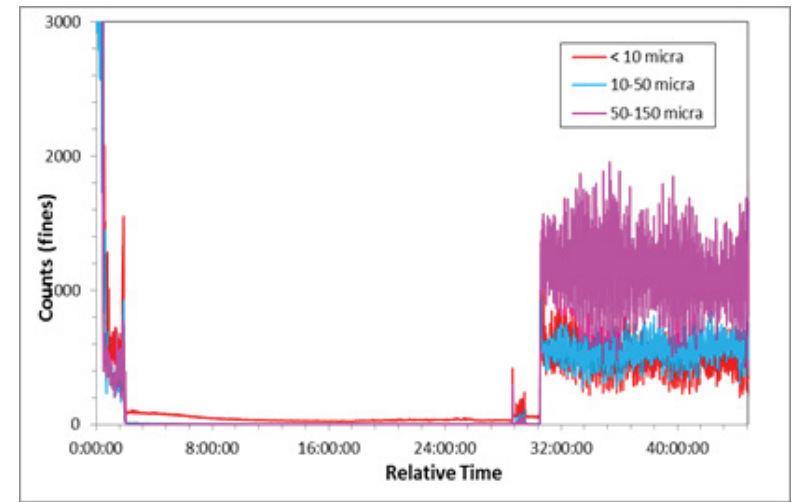

Figure 13: FBRM measure of pre-filtered live oil in a high pressure loop, simulating a depletion scenario - Full pressure decreasing.

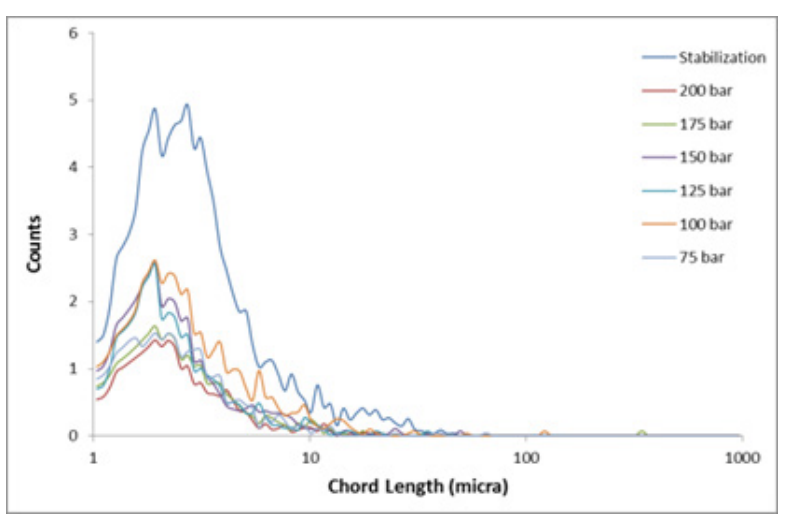

Figure 14: Distribution of chord length of pre-filtered live oil in one only pressure step.
The test continues with the depressurizing of the circuit up to a pressure close to 50 bars. At this time, the circuit was diverted to the filtration process for two hours. At the end of this experiment, the circuit is depressurized below 50 bars and monitored for approximately 10 hours to observe separation of the methane dissolved in the oil.

The first test was carried out with the objective of observing the formation of asphaltenes due to steeps of decreasing the pressure. In this case, an unfiltered sample of crude oil and methane was properly recombined. After been charged the live oil setting at 200 bars and $65^{\circ} \mathrm{C}$ the system was kept constant. The Figure 14 displays the variation of counts against the time. The procedure was established with backpressure valve which can decrease gradually the pressure in an interval of two hours.

After the first two hours from charge of live oil in the circuit, it is observed in Figure 15 that the FBRM signal has a count of 5660 for particles with diameter $<10$ microns, while the particle count $>10$ microns the count showed a value on the average of 1000 . At this time the circuit was carried out the depressurized from 200 to 175 bars. During this period, an increase of approximately $20 \%$ (1000 counts) was shown for particles $<10$ microns as shown in Figure 16. Still, in this figure, it can be seen that the particle count of 10-50 microns did not show significant changes. With the second system depressurizing (175-150 bars), the count remained constant at the value of the lower 10-micron particles showing in the first hour an increase in counting, followed by a decrease to a count of 6833 . After this pressure value, the

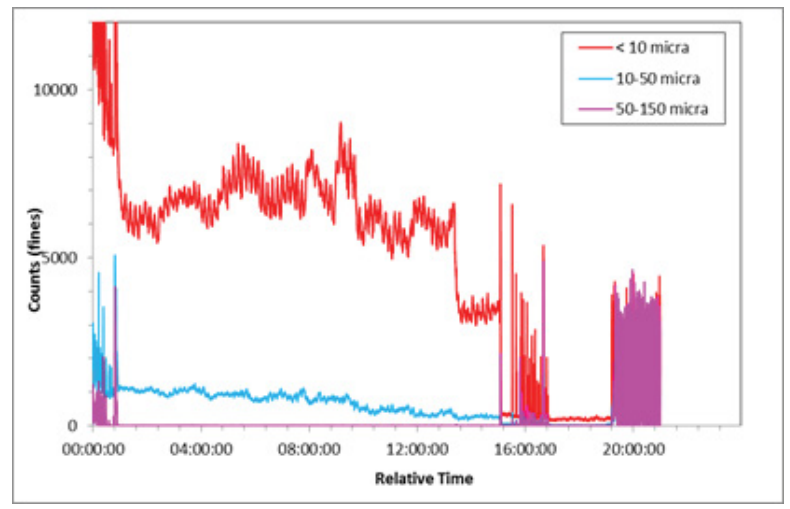

Figure 15: FBRM measure of non-filtered live oil in a high pressure loop simulating a depletion scenario - pressure steps.

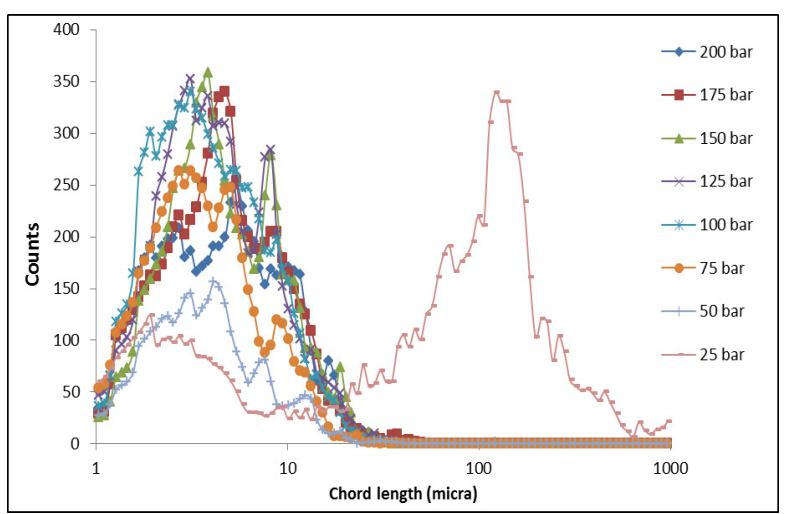

Figure 16: Distribution of chord length of the non-filtered live oil in one only pressure step. 
Citation: Ruidiaz EM, Koroishi ET, Kim NR, Trevisan OV, Soares-Bassani G, et al. (2018) Evaluation of Asphaltene Deposition - A Systematic Study and Validation of Online Focused Beam Reflectance Measurement FBRM ${ }^{\circledR}$ at Reservoir Conditions. J Pet Environ Biotechnol 9: 364. doi: $10.4172 / 2157-7463.1000364$

Page 7 of 8

scale of the particle counting axis was changed for better observation. The next steeps of decreasing pressure from 150-125 bars, the same trend was observed in this stage of the previous depressurizing steep, reaching values of the order of 8000 counts. The particles between 10 50 microns exhibit a constant count of approximately 1000 counts. When the pressure was decreased at 125 - 100 bars the count increased $40 \%$ in particles $<10$ microns, this value is compared to that obtained at the pressure of 200 bars (5660 counts) which can be associated to asphaltene growing.

In the fifth depressurizing step of the circuit, it was observed that the count decreased to the value close to the reference count of the experiment (5600 counts) during the last depressurizing step, variations similar to the previous pressures were observed, which shows that the asphaltenes formation and flocculation process occurs during all the pressure values evaluated in this experiment. To validate this effect, the system was monitored for the following 8 hours.

After reach the pressure of 50 bars a decreasing in counting was observed well beyond the reference value observed for this experiment for both the observed particles, $<10$ microns and 10-50 microns. The live oil was passed through the filter to carry out the retention process of the crystallized asphaltenes during the depressurizing process. As seen in the same figure, the count decreases significantly for approximately 20 min until a variation in count occurs. After completion of the twohour filtering time, the by-pass was bypassed and the oil was circulated for another two hours, Figure 16 shows between hours 18-20 counting down to 100 count counts which mean that the filtering process was performed properly. From the 20 hours of the experiment, the system was depressurized to 25 bars and the separation of methane dissolved in the oil recombination was observed. The same figure shows the behavior of the count of several particle sizes, as well as the rope length distribution.

\section{Discussion}

As observed in the previous experiments, the formation of asphaltenes during each depressurizes stage of the system evidence that FBRM's can identify the particle size and the trend of evolution regarding composition to pre-filtered oil. The term asphaltenes formation corresponds to the phenomenon of crystallization of the molecules dissolved in the oil and that during the pressure drop crystals of the being suspended in the oil are formed. The results of these experiments showed that for both the unfiltered oil sample and the filtered oil the appearance of asphaltenes (increase of the count) is favored by the successive pressure drop, in both, for the pressure range of $100-75$ bars the increment was higher than in all other pressure values studied during the experiments.

The results obtained in the first experiment (Figure 13) show that the unfiltered oil has a higher count in the target particles of investigation and yet the percentages obtained during each pressurizing step are close between each stage. Still, this count has already been observed in previous experiments, with paraffin and resins being one of the hypotheses attributed to this effect. To address this problem, oil samples were collected at various points in the experiment and the asphaltenes contents were checked.

During the second experiment, the sample of filtered oil and properly recombined with methane was used. The same procedure was applied for this experiment. In this case, successive increases in the count of target particles were detected at all stages of depressurizing, having increases in an order of $66 \%$ relative to the reference value obtained in the first part of the experiment.
In this experiment, a stabilization step was performed to observe the decrease in the count due to the solubilization of the asphaltenes contained in the oil. As seen in Figure 13, the count was monitored for approximately 10 hours. As a result of this, it can be concluded that there is a decrease in the initial count which is interpreted as the dissolution of asphaltene due to the pressure of 200 barss. Subsequently, the system was depressurized follow the same procedure as previous experiments.

The filtration process used in these experiments showed an effect that has not yet been analyzed, due to the fact that for the first experiment, this process presented a decrease of approximately $98 \%$ relative to the initial value of the 5600 count. In the second experiment, the count presented an increase followed by stabilization at a value higher than that observed during stabilization of the system. These effects may be due to the interference of the oil contained in the by-pass (filter); this oil sample remained in the system without contact with the oil of the working circuit. Therefore, it is believed that the mixture of the two oils, even though it is the same fluid, one portion has changed properties during the depressurizing process and another does not. This effect may be due to the fact that this oil was previously filtered and an important portion of asphaltenes was removed, which is one of the hypotheses to explain why after filtering the oil from the circuit the count does not decrease but increases.

\section{Conclusions}

During the execution of this experiment, several effects were found, which will be summarized below.

1. It was confirmed that during the single-stage depressurization there was an increase in the length of the rope that can be attributed to the formation (crystallization) of asphaltenes confirming that observed in previous experiments. Also, it has been shown that during the depressurizing of the circuit, there is a tendency for the asphaltenes to separate (asphaltene formation), an increase of the length of the rope and subsequent decrease of the asphaltenes, which indicates that formation occurs, followed by agglomeration and coalescence in the due to the flow regime. The kinetics of asphaltenes found in this experiment showed that the stabilization time promotes the dissolution in the oil and as the pressure decreases the crystallization of the asphaltene increases.

2. It was confirmed that during the entire pressure range there was an increase in the count attributed to the formation (crystallization) of asphaltenes, with the effect being greater between $100-75$ bars. Significant variations in counts were observed when unfiltered oil was used, probably because in this sample the asphaltene content interacts in a reversible process, producing close values when the system returns to a reference pressure value.

3. Tests with live oil were successfully performed within the operational limitations of the equipment, showing that the FBRM presents reliable measurements at high temperatures and pressures.

\section{Acknowledgments}

The authors of this work would like to thank to ANP, Repsol Sinopec Brazil and CEPETRO for financial support.

\section{References}

1. Calles JA, Dufour J, Marugan J, Peña JL, Aguirre RG (2008) Properties of 
Citation: Ruidiaz EM, Koroishi ET, Kim NR, Trevisan OV, Soares-Bassani G, et al. (2018) Evaluation of Asphaltene Deposition - A Systematic Study and Validation of Online Focused Beam Reflectance Measurement FBRM ${ }^{\circledR}$ at Reservoir Conditions. J Pet Environ Biotechnol 9: 364. doi: $10.4172 / 2157-7463.1000364$

Page 8 of 8

asphaltenes precipitated with different $n$-alkanes. A study to assess the most representative species for modeling. Energy Fuels 22: 763-769.

2. Leontaritis KJ, Mansoori AG (1988) Asphaltene deposition: A survey of field experiences and research approaches. J Pet Sci Eng 1: 229-239.

3. Ameli F, Hemmati-Sarapardeh A, Dabir B, Mohammadi AH (2016) Determination of asphaltene precipitation conditions during natural depletion of oil reservoirs: A robust compositional approach. J. Fluid Phase Equilib 412: 235-248.

4. Nghiem L, Hassam M, Nutakki R, George A (1993) Efficient modelling of asphaltene precipitation. SPE Annual Technical Conference and Exhibition, Society of Petroleum Engineers.

5. Afshari S, Kharrat R, Ghazanfari MH (2016) Asphaltene precipitation study during natural depletion at reservoir conditions. Iranian J Oil Gas Sci Tech 2 : 45-65.

6. Mousavi-Dehghani S, Riazi M, Vafaie-Sefti M, Mansoori G (2004) An analysis of methods for determination of onsets of asphaltene phase separations. J Pet Sci Eng 42: 145-156.

7. Tavakkoli M, Grimes MR, Liu X, Garcia CK, Correa SC, et al. (2015) Indirect method: A novel technique for experimental determination of asphaltene precipitation. Energy Fuels 29: 2890-2900.

8. Al-Nasser WN, Al-Salhi FH (2013) Scaling and aggregation kinetics determination of calcium carbonate using inline technique. Chem Eng Sci.86: 70-77.

9. Gregory J (2009) Monitoring particles and aggregates. Adv Colloid Interface Sci 147-148: 109-123.

10. Yu W, Erickson K (2008) Chord length characterization using focused beam reflectance measurement probe - Methodologies and pitfalls. Powder Techno 185: $24-30$.

11. Hukkanen EJ, Braatz RD (2003) Measurement of particle size distribution in suspension polymerization using in situ laser backscattering. Sensor Actuat B 96: 451-459.

12. Li M, Wilkinson D, Patchigolla K (2005) Comparison of particle size distributions measured using different techniques. Particles Sci Technol 23: 265-284.

13. Coto MC, Peña B, Rodríguez JL, Merino-Garcia D, Pastor G (2010) Effect of precipitation procedure and detection technique on particle size distribution of $\mathrm{CaCO}_{3}$. J Cryst Growth 312: 2756-2763. 